\title{
Physical Comorbidity Among Elderly Schizophrenics: A Native Evaluation in Iran
}

\author{
Saeed Shoja Shafti ${ }^{1 *}$, Alireza Memarie ${ }^{2}$, Masomeh Rezaie ${ }^{2}$ and Behjat Rahimi² \\ ${ }^{1}$ University of Social Welfare and Rehabilitation Sciences [USWR], Razi Psychiatric Hospital Tehran, Iran
}

${ }^{2}$ Department of Psychology, Razi Psychiatric Hospital Tehran, Iran

*Corresponding author: Saeed Shoja Shafti, University of Social Welfare and Rehabilitation Sciences [USWR] Razi Psychiatric Hospital Tehran, Iran

\begin{abstract}
Introduction: Comorbidity between mental disorders and physical illnesses is the rule rather than the exception. Approaches to study the impact of comorbidity become challenging also due to lack of consensus about how to define and measure the concept of comorbidity. The aim of the present study was to evaluate the clinical profile of medical comorbidity among a group of local chronic elderly schizophrenic patients to see their prevalence and physiognomies.

Methods: while geriatric section of Razi psychiatric hospital had been selected as the field of investigation, all elderly schizophrenic patients, who have been hospitalized there for lifelong, had been selected as accessible sample and surveyed with respect to recorded checkups and comorbid medical diagnoses. Psychiatric diagnosis was in essence based on 'Diagnostic and Statistical Manual of Mental Disorders', $5^{\text {th }}$ edition [DSM-5] and medical diagnosis was principally based on 'International Classification of Diseases', $10^{\text {th }}$ edition.

Results: Assessment had been performed on 168 aged schizophrenic patients ( $\geq 65$ years old), including 101 men and 67 women. According to results, $89 \%$ [n=151] of elderly patients had some kind of registered non-psychiatric co-morbidity, which was meaningfully higher than frequency of comorbidity among senior group of local residents. Amongst recorded co-morbidities falls, hypertension and osteoarthritis were the most prevalent comorbidities with a frequency around 48.8\%, 44.6\% and 39.2\%, respectively. Hypertension, renal disease and malnutrition were significantly more prevalent among male patients $(\mathrm{p}<0.0000$, $\mathrm{p}<0.0045$ and $\mathrm{p}<0.0018$, in turn) and hyponaremia, aspiration/asphyxiation and seizure were meaningfully more prevalent among female patients $(\mathrm{p}<0.0075, \mathrm{p}<0.0000$ and $\mathrm{p}<0.0009$, one-to-one). As stated by the findings and in comparison with the senior group of local people while diabetes, renal diseases and malnutrition were significantly more frequent, coronary artery disease, gastrointestinal disorder and osteoarthritis were significantly less frequent among the present sample of elderly schizophrenic patients.

Conclusion: While in comparison with senior group of local people the rate of medical co-morbidities, particularly diabetes, renal diseases and malnutrition, were significantly higher in chronic elderly schizophrenic patients, a significant difference, as well, was palpable regarding the interrelated items between male and female patients, which demands further methodical and genderbased studies to define proper care and interventions for this vulnerable group of patients.
\end{abstract}

Keywords: Schizophrenia; Psychiatric disorders; Medical comorbidity; Elderly mental patients; Senior group of people; Chronic patients

\section{Introduction}

Perhaps, comorbidity between mental disorders and physical sicknesses is the rule rather than the exception [1]. It is estimated that although $25 \%$ of adult population have mental health illness, $68 \%$ of them suffer from comorbid medical disease [2]. While readmission rates in psychiatric patients are high and we still lack understanding its likely predictors, physical co-morbidity could be one of important risk factors for psychiatric readmission [2]. On the other hand, while the term 'comorbidity' is well-acknowledged in research and clinical settings, the idea remains complicated and methodological approaches are different [3]. So, there is now 
no agreement about the definition of comorbidity, which can be defined in several different methods [3]. In general, the term comorbidity has three meanings: Indicating a medical sickness in a patient existing concurrently but independently with another condition; Representing a medical disease in a patient that causes, is caused by, or is otherwise related to another ailment in the same patient; Indicative of two or more medical sicknesses in a patient that exist at the same time, regardless of their causative association [4].

In an inclusive trial of integrating different aspects of comorbidity, authors have combined different constructs and measures associated with the core concept of comorbidity. Hence, in this respect, four major distinctions were made according to the nature of the health condition, the relative importance of the co-occurring conditions, and the chronology of the conditions: comorbidity, multimorbidity, morbidity burden and patient's complexity $[5,6]$. On the other hand, there is growing interest among physicians and scholars in the impact of comorbidity on a range of outcomes, such as mortality, health-related quality of life, patient's functioning, and health care utilization [7]. For instance, physical comorbidities, basic demographic data, and clinical variables have shown to much better foretell mortality than the risk of readmission [8]. Also, in patients with comorbidities, along with the higher risk of dying, a poorer functional status, quality of life, and a greater use of health services has been recounted [8]. These conclusions led to the inference that among patients with comorbidity, the focus of health care should not only be on one particular ailment, but, besides, on the pathology in other organs and on indicators for quality of care, such as complications of management, readmissions, treatment plans and compliance to generally accepted clinical recommendations [9, 10]. Earlier studies on patients with serious mental ailment such as longlasting schizophrenia, bipolar disorder, or protracted recurrent depression, have revealed that these patients have higher mortality rates than persons without serious mental disorder [11]. This variance is partially explained as being produced by increases in comorbid medical disorders in the mentally ill, frequently chronic diseases such as diabetes [12] and cardiovascular disease [13]. Alternatively, though there is an assumption that patients with serious mental sickness experience a shortened life expectancy due to increased mortality and few of these patients would survive until old age [14], there is now evidence that the numbers of these old mentally ill survivors is increasing $[15,16]$. As stated by a study, patients with serious mental disorder had significantly higher rates of medical emergency room visits and meaningfully longer lengths of medical hospitalizations than did the primary care control group [17], and for depressed aged persons with at least one chronic medical ailment, improvements in clinical management and harmonization of medical and mental health amenities could moderate the rate of utilization of services [18]. Furthermore, as said by another study on senior persons, readmission was most likely among persons with a primary diagnosis of schizophrenia, followed by bipolar disorder, depression, and substance abuse [19]. Likewise, comorbid severe mental illness in patients with diabetes is individually linked with greater risk of early medical or surgical re-hospitalization [20]. Besides, while health-risk behaviors (e.g., smoking, poor diet, and sedentary lifestyle) contribute to these poor outcomes, treatment with second generation antipsychotic drugs as well has been associated with poorer glycemic control among patients with diabetes [21]. Alternatively, patients with serious mental conditions appear to under-utilize primary care services [22] and consequently increase the risk of medical hospitalizations due to possibly avoidable complications [23]. Additionally, these patients may be at heightened risk of in-hospital adverse events, too, such as nosocomial infections and postoperative complications [24]. Nevertheless, another study had found no increased risk due to these comorbidities [25]. The aim of the present evaluation was to appraise the prevalence and physiognomies of medical comorbidities among a group of native elderly schizophrenic patients.

\section{Methods}

Razi psychiatric hospital in south of capital city of Tehran, as one of the largest and oldest public psychiatric hospitals in the Middle East, which has been established formally in 1917 and with a capacity around 1375 active beds, had been selected as the field of study in the present retrospective assessment. So, amongst its separate existent sections, chronic geriatric section of hospital with a capacity around 220 beds ( 110 for male and female aged patients, separately) had been designated as the specific field of investigation. Thus, for assessment, all chronic elderly schizophrenic patients ( $\geq 65$ years old), as accessible sample, had been nominated and estimated with respect to registered checkups and comorbid medical conditions. Psychiatric diagnosis was principally based on 'Diagnostic and Statistical Manual of Mental Disorders', $5^{\text {th }}$ edition [DSM-5] [26] and medical diagnosis was principally based on 'International Statistical Classification of Diseases and Related Health Problems', $10^{\text {th }}$ Revision [27].

\section{Statistical Analysis}

Descriptive statistics including means, standard deviations, and ranges for continuous variables and quantity or percent in each category for categorical variables were calculated for all characteristics. T-tests for continuous data and chi-square tests for categorical data were used to compare the necessary variables between genders or groups. Statistical significance, as well, had been defined as $p$ value $\leq 0.05$. MedCalc Statistical Software version 15.2 was used as statistical software tool for analysis.

\section{Results}

According to the findings, the current assessment of elderly schizophrenic patients had been performed on one hundred and sixty-eight patients, including one hundred and one males and sixtyseven females, who had been hospitalized in the chronic section of the hospital for long-life. Mean age $[ \pm S D]$ of the patients were around $69.12 \pm 8.93$ and $74.69 \pm 6.54$ for male and female patients, respectively, which was significantly shorter for male patients $[\mathrm{t}=$ $-4.383, \mathrm{p}<0.00$, CI $95 \%=-8.08,-3.06]$. As said by results, nearly 
$89 \%$ [n=151] of aged patients had some kind of registered nonpsychiatric co-morbidity, usually between one to four problems, that required specific care by a primary care physician or specialist, and so had received related standard cares, visits and treatments, on a regular basis (Table 1). This amount of medical comorbidity was significantly higher in comparison with the local aged group of people with about $80 \%$ comorbidity [z=-3.2458, p<0.0012, CI $95 \%=-0.1761,-0.0435]$ [28] (Table 2).

Table 1: Prevalence of medical co-morbidities among elderly schizophrenic patients.

\begin{tabular}{|c|c|c|}
\hline Co-morbidity & Number & Percentage \\
\hline Falls & 82 & 48.8 \\
\hline Hypertension & 75 & 44.6 \\
\hline Osteoarthritis & 51 & 30.3 \\
\hline Malnutrition & 64 & 30 \\
\hline Aspiration / Asphyxiation & 49 & 29.1 \\
\hline Prostate enlargement & 28 & 27.7 \\
\hline Diabetes & 39 & 23.2 \\
\hline Seizure & 34 & 20.2 \\
\hline Renal disease & 33 & 19.6 \\
\hline Bed sore & 30 & 17.8 \\
\hline Hyponatremia & 27 & 16 \\
\hline Coronary artery disease & 25 & 14.8 \\
\hline Gastrointestinal disorder & 14 & 8.3 \\
\hline Cataract & 14 & 8.3 \\
\hline Hypothyroid & 13 & 7.7 \\
\hline Chronic obstructive pulmonary disease & 13 & 7.7 \\
\hline Liver disease & 13 & 7.7 \\
\hline Anemia & 9 & 5.3 \\
\hline Congestive heart failure & 7 & 4.1 \\
\hline Cancer & 7 & 4.1 \\
\hline Stroke & 5 & 2.9 \\
\hline Hyperthyroid & 5 & 2.9 \\
\hline Parkinson disease & 5 & 2.9 \\
\hline Brain cyst & 1 & 0.5 \\
\hline
\end{tabular}

Table 2: Elderly schizophrenic patients versus senior group of local people, as regards the frequency of medical co-morbidities.

\begin{tabular}{|c|c|c|c|c|c|}
\hline Comorbidity & Elderly schizophrenic patients(Percentage) & Senior group of local people(Percentage) & $\mathbf{Z}$ & $\mathbf{P}$ & CI \\
\hline Diabetes & $23.2 \%$ & $15.6 \%$ & 2.36 & 0.01 & $-0.14,-0.01$ \\
\hline Hypertension & $44.6 \%$ & $41.5 \%$ & 0.75 & 0.44 & $-0.11,0.05$ \\
\hline $\begin{array}{l}\text { Chronic obstructive } \\
\text { pulmonary disease }\end{array}$ & $7.73 \%$ & $10.8 \%$ & 1.18 & 0.23 & $-0.02,0.08$ \\
\hline $\begin{array}{c}\text { Coronary artery } \\
\text { disease }\end{array}$ & $14.8 \%$ & $37.5 \%$ & 5.07 & 0.00 & $0.12,0.28$ \\
\hline Renal disease & $19.6 \%$ & $6 \%$ & 5.62 & 0.00 & $-0.18,-0.08$ \\
\hline Malnutrition & $30 \%$ & $5.8 \%$ & 11.32 & 0.00 & $-0.37,-0.26$ \\
\hline $\begin{array}{l}\text { Gastrointestinal } \\
\text { disorder }\end{array}$ & $8.33 \%$ & $45.89 \%$ & 8.92 & 0.00 & $0.29,0.45$ \\
\hline Osteoarthritis & 30.35 & 79.2 & 12.74 & 0.00 & $0.42,0.58$ \\
\hline
\end{tabular}

Listed co-morbidities included diabetes, hypertension, falls, congestive heart failure, chronic obstructive pulmonary disease, osteoarthritis, cancer, coronary artery disease, liver disease, renal disease, stroke, thyroid disease, bed sore, aspiration/ asphyxiation, seizure, hyponatremia , malnutrition , anemia
, gastrointestinal bleeding, prostate enlargement, cataract, Parkinson disease and brain cyst [Table 1]. Among them falls, hypertension and osteoarthritis were the most prevalent disorders with a percentage around $48.8 \%, 44.6 \%$ and $30.35 \%$, respectively [Table 1]. The next co-morbidities included malnutrition (30\%), 
aspiration/asphyxiation (29.1\%), prostate enlargement (27.7\%), diabetes $(23.2 \%)$, seizure $(20.2 \%)$, renal disease $(19.6 \%)$, bed sore $(17.8 \%)$, hyponatremia $(16 \%)$, coronary artery disease (14.8\%), gastrointestinal disorder (8.33\%), cataract (8.33\%), liver disease $(7.73 \%)$ and hypothyroidism $(7.73 \%)$. The remaining comorbidities, including congestive heart failure, chronic obstructive pulmonary disease, cancer, stroke, anemia, Parkinson disease and brain cyst, were less than six percent, individually. As said by the findings, hypertension, renal disease and malnutrition were significantly more prevalent among male patients $(\mathrm{p}<0.0000$, $\mathrm{p}<0.0045$ and $\mathrm{p}<0.0018$, in turn) and hyponaremia, aspiration/ asphyxiation and seizure, were significantly more prevalent among female patients $(\mathrm{p}<0.0075, \mathrm{p}<0.0000$ and $\mathrm{p}<0.0009$, one-toone) (Table 3). According to the findings and in comparison with the senior people of local people, while diabetes, renal diseases and malnutrition were significantly more frequent, coronary artery disease, gastrointestinal disorder and osteoarthritis were significantly less frequent among the present sample of chronic old schizophrenic patients (Table 3).

Table 3: Prevalence of medical co-morbidities among male and female elderly schizophrenics.

\begin{tabular}{|c|c|c|c|c|c|c|c|}
\hline Comorbidity & Males (n=101) & $\%$ & Females $(n=67)$ & $\%$ & $\mathbf{Z}$ & $\mathbf{P}$ & CI \\
\hline Diabetes & 28 & 27.7 & 11 & 16.4 & 1.69 & 0.08 & $-0.01,0.24$ \\
\hline Hypertension & 60 & 59.4 & 15 & 22.3 & 4.72 & 0.00 & $0.21,0.52$ \\
\hline Falls & 47 & 46.5 & 35 & 52.2 & 0.72 & 0.46 & $-0.21,0.09$ \\
\hline Congestive heart failure & 4 & 3.96 & 3 & 4.47 & 0.16 & 0.86 & $-0.06,0.05$ \\
\hline Chronic obstructive pulmonary disease & 8 & 3.9 & 5 & 2.9 & 0.10 & 0.91 & $-0.07,0.08$ \\
\hline Osteoarthritis & 29 & 28.71 & 22 & 32.83 & 0.56 & 0.56 & $-0.18,0.10$ \\
\hline Cancer & 4 & 3.9 & 3 & 4.4 & 0.16 & 0.86 & $-0.06,0.05$ \\
\hline Coronary artery disease & 13 & 12.8 & 12 & 17.9 & 0.89 & 0.36 & $-0.16,0.05$ \\
\hline Liver disease (hepatitis) & 9 & 8.9 & 4 & 5.97 & 0.69 & 0.17 & $-0.05,0.11$ \\
\hline Renal disease & 27 & 26.7 & 6 & 8.9 & 2.83 & 0.00 & $0.05,0.30$ \\
\hline Stroke & 4 & 3.9 & 1 & 1.4 & 0.92 & 0.35 & $-0.02,0.07$ \\
\hline Hyperthyroid & 3 & 2.97 & 2 & 2.98 & 0.005 & 0.99 & $--0.05,0.05$ \\
\hline Hypothyroid & 8 & 7.92 & 5 & 7.46 & 0.10 & 0.91 & $-0.07,0.08$ \\
\hline Bed sore & 14 & 13.8 & 16 & 23.8 & 1.66 & 0.09 & $-0.21,0.01$ \\
\hline Aspiration / Asphyxiation & 17 & 16.8 & 32 & 47.7 & 4.31 & 0.00 & $-0.44,-0.16$ \\
\hline Seizure & 12 & 11.8 & 22 & 32.8 & 3.31 & 0.00 & $-0.33,-0.08$ \\
\hline Hyponatremia & 10 & 9.9 & 17 & 25.3 & 2.67 & 0.00 & $-0.26,-0.04$ \\
\hline Malnutrition & 50 & 49.5 & 14 & 20.8 & 3.12 & 0.00 & $0.09,0.39$ \\
\hline Anemia & 5 & 4.9 & 4 & 5.9 & 0.28 & 0.77 & $-0.07,0.05$ \\
\hline Gastrointestinal disorder & 9 & 8.91 & 5 & 7.46 & 0.33 & 0.73 & $-0.07,0.09$ \\
\hline Prostate enlargement & 28 & 27.7 & - & - & - & -- & - \\
\hline Cataract & 8 & 7.92 & 6 & 8.95 & 0.23 & 0.81 & $-0.09,0.07$ \\
\hline Parkinson disease & 3 & 2.97 & 2 & 2.98 & 0.00 & 0.99 & $-0.05,0.05$ \\
\hline Brain cyst & 1 & 0.9 & 0 & 0 & - & - & - \\
\hline
\end{tabular}

\section{Discussion}

While the co-occurrence of mental and physical conditions is very common in clinical settings, the exact nature of relationship between them is very complex and hitherto not well understood [29]. So far, very little work has been done on medical comorbid disorders among patients with mental illnesses since comorbidity was rarely the main objective of studies [5]. Additionally, while comorbidity is generally associated with mortality, consequences of specific disease combinations depend on many issues [11]. It is clear that in elderly people, each body system undergoes changes, which occur over many years and are considered normal among senior people [10] However, these changes often place the elderly persons at high risk for the development of various diseases [15]. So, it is very important to differentiate normal from pathological alterations in order to prevent wrongly treatment of normal changes and failing to treat those that result from ailments [29]. Back to our discussion and with respect to clinical profile of medical comorbidity among senior schizophrenic patients, almost most of patients had some kind of registered non-psychiatric co-morbidity that demanded specific attention by a primary care physician or specialist. Thus, in comparison with senior group of local people [28] a significantly higher proportion of comorbidity was evident among the present sample.

Such a finding was in harmony with the outcomes of $[12,5,7]$ who believed that psychiatric patients have been widely reported to be at an increased risk of morbidity and mortality due to physical disorders and comorbidity between medical and mental disorders is the rule rather than the exception. But it was not in harmony with 
the conclusions of Daumit et al. [25], who had found no significant increased risk of morbidity or mortality associated with the presence of these comorbidities in severe mental patients. Besides, among the listed comorbidities in current assessment, falls, hypertension and osteoarthritis were the most prevalent medical complications. These outcomes are partially consistent with the findings [17], who had found hypertension, osteoarthritis and diabetes as the most prevalent medical comorbidities among aged mental patients. But in contrary to him, in the present assessment there was not any significant difference regarding prevalence of hypertension between the present sample of schizophrenics and senior group of local people. Besides, while his claim regarding higher prevalence of falls in comparison with the primary care controls was not approvable here, due to deficiency of reliable native recording, falls was meaningfully higher among our patients, in comparison with other recorded items.

Anyhow, the impact of demographic variances should not be ignored, since his samples included more females, a variety of ethnic groups and outpatients from primary care clients, while our samples included more males, single ethnic group (Persians), and only inpatients. Also with respect to other major co-morbidities in the present assessment, like malnutrition, diabetes, seizure, renal disease, coronary artery disease, gastrointestinal disorder and hypothyroidism, our findings were to some extent in harmony with reports [30-37] who had found, as a general rule, infections, lung, gastrointestinal, urogenital and cardiovascular diseases as the most prevalent medical comorbidities among severe mental patients; Because they were comparable only with respect to urogenital and cardiovascular diseases. Our results regarding the remaining rarer co-morbidities, like congestive heart failure, chronic obstructive pulmonary disease, cancer and stroke, again, were not coherent with the outcomes $[17,36]$. Furthermore, since medical problems like, bed sore, aspiration/asphyxiation, seizure, hyponatremia and malnutrition, had not been pointed out or surveyed in the parallel studies, further assessment becomes difficult. On the other hand, as said by the conclusions of the current evaluation, hypertension, renal disease and malnutrition were significantly more prevalent among male patients and hyponaremia, aspiration/asphyxiation and seizure, were meaningfully more prevalent among female patients, which may display a gender-based difference in this regard. While such a difference could depend partly on the route of care, and somewhat on biological grounds, it may perhaps offer facts for future studies, too. Likewise, in comparison with the local senior persons, diabetes, renal diseases and malnutrition were significantly more frequent among the present sample of chronic elderly schizophrenic patients, a finding which was again, unharmonious with the findings [17].

Anyhow, while the impact of physical comorbidity on psychiatric readmission is still unsatisfactorily investigated problem, there is a growing interest among specialists and academics in the impact of physical comorbidity on a variety of outcomes in mental disorders, such as mortality, health-related quality of life and health care spending, which is noticeably higher for patients with comorbid disorders [10]. The comorbidity of mental and physical disorders is on the increase and as pointed out by Sartorius this topic is becoming a main challenge to medicine in the $21^{\text {st }}$ Century [14]. Future research should address these topics with more in-depth studies since new understandings in this field could lead to better prevention approaches to reduce psychiatric readmissions [37]. In this regard, teaching regarding the normal changes of aging should be the first intervention made with all aging adults to help them understand what is going on in their bodies. In addition, many interventions are available to compensate for these changes as well as to prevent the development of disease as a consequent of these interventions [29]. Short duration of assessment, small sample size, restriction of study to a single academic center and lack of parallel and concomitant control groups, were among the weaknesses of the present evaluation. Surely, further methodical researches are needed to define proper care and interventions for this vulnerable group of patients.

\section{Conclusion}

While in comparison with senior group of local people the rate of medical co-morbidities, particularly diabetes, renal diseases and malnutrition, were significantly higher in chronic elderly schizophrenic patients, a significant difference, as well, was palpable regarding the interrelated items between male and female patients, which demands further methodical and gender-based studies to define proper care and interventions for this vulnerable group of patients.

\section{References}

1. Šprah L, Zvezdana Dernovšek M, Wahlbeck K, Haaramo P (2017) Psychiatric readmissions and their association with physical comorbidity: A systematic literature review. BMC Psychiatry 17: 2.

2. Cloninger RC (2002) Implications of Comorbidity for the Classification of Mental Disorders: The Need for a Psychobiology of Coherence. In: Maj M, Gaebel W López-Ibor JJ, Sartorius N, (Eds). Psychiatric Diagnosis and Classification. West Sussex: Wiley pp. 79-106.S

3. AIHW (Australian Institute of Health and Welfare) (2007). Comorbidity of mental disorders and physical conditions, Canberra, Australia.

4. Egede LE (2007) Major depression in individuals with chronic medical disorders: Prevalence, correlates and association with health resource utilization, lost productivity and functional disability. Gen Hosp Psychiatry 29(5): 409-416.

5. Andrés E, Garcia-Campayo J, Magán P (2012) Psychiatric morbidity as a risk factor for hospital readmission for acute myocardial infarction: An 8-year follow-up study in Spain. International Journal Psychiatry Medicine 44(1):63-75.

6. Jakovljević M, Ostojić L (2013) Comorbidity and multimorbidity in medicine today: Challenges and opportunities for bringing separated branches of medicine closer to each other. Psychiatry Danub 2 (1): 1828.

7. Vigod SN, Taylor VH, Fung K, Kurdyak PA (2013) Within-hospital readmission: an indicator of readmission after discharge from psychiatric hospitalization. The Canadian Journal of Psychiatry 58(8): 476-481.

8. Kessing LV, Nilsson FM, Siersma V, Andersen PK (2004) Increased risk of developing diabetes in depressive and bipolar disorders? Journal of Psychiatry Research 38(4): 395-402.

9. Morrow-Howell NL, Proctor EK, Blinne WR, Rubin EH, Saunders JA, et al. (2006) Post-acute dispositions of older adults hospitalized for depression. Aging \& Mental Health 10(4): 352-361. 
10. Elixhauser A, Steiner C, Harris DR, Coffey RM (1998) Comorbidity measures for use with administrative data. Med Care 36: 8-27.

11. De Hert M, Cohen D, Bobes J (2011) Physical illness in patients with severe mental disorders. II. Barriers to care, monitoring and treatment guidelines, plus recommendations at the system and individual level. World Psychiatry 10: 138-151.

12. Brown S, Kim M, Mitchell C (2010) Twenty-five year mortality of a community cohort with schizophrenia. Br J Psychiatry 196: 116-121.

13. Laursen TM, Munk-Olsen T, Agerbo E (2009) Somatic hospital contacts, invasive cardiac procedures, and mortality from heart disease in patients with severe mental disorder. Arch Gen Psychiatry 66(7): 713-720.

14. Tosh G, Clifton A, Mala S (2010) Physical health care monitoring for people with serious mental illness. Cochrane Database System Review.

15. Harvey PD, Czaja SJ, Loewenstein DA (2012) Schizophrenia in later life. Am J Geriatr Psychiatry 20: 1-4.

16. Jeanne Dickens, Malaz A, Boustani MPH, Christopher M, Callahan MD (2013) Comorbidity Profile and Health Care Utilization in Elderly Patients with Serious Mental Illnesses. The American Journal of Geriatric Psychiatry 21(12): 1-14.

17. Hendrie HC, Hay D, Lane KA (2013) Comorbidity Profile and Health Care Utilization in Elderly Patients with Serious Mental Illnesses. The American Journal of Geriatric Psychiatry 21(12): 1-14.

18. Himelhoch S, Weller WE, Wu AW, Anderson GF, Cooper LA (2004) Chronic medical illness, depression, and use of acute medical services among Medicare beneficiaries. Med Care 42(6): 512-521.

19. Prince JD, Akincigil A, Kalay E (2008) Psychiatric rehospitalization among elderly persons in the United States. Psychiatry Services 59(9): 1038-1045.

20. Chwastiak LA, Davydow DS, McKibbin CL (2014) The Impact of Serious Mental Illness on the Risk of Rehospitalization among Patients with Diabetes. Psychosomatics 55(2): 134-143.

21. Bennett KJ, Probst JC, Vyavaharkar M, Glover S (2012) Missing the handoff: post-hospitalization follow- up care among rural Medicare beneficiaries with diabetes. Rural Remote Health 12: 2097.

22. Garrison GM, Mansukhani MP, Bohn B (2013) Predictors of thirty-day readmission among hospitalized family medicine patients. Journal of American Board Family Medicine 26(1): 71-77.

23. Calvillo-King L, Arnold D, Eubank KJ, Lo M, Yunyongying P, et al. (2013) Impact of social factors on risk of readmission or mortality in pneumonia and heart failure: Systematic review. J Gen Intern Med 28(2): 269-282.

24. Himelhoch S, Leith J, Goldberg R, Kreyenbuhl J, Medoff D, et al. (2009) Care and management of cardiovascular risk factors among individuals with schizophrenia and type 2 diabetes who smoke. General Hospital Psychiatry 31(1): 30-32.

25. Daumit GL, Pronovost PJ, Anthony CB, Guallar E, Steinwachs DM, et al. (2006) Adverse events during medical and surgical hospitalizations for persons with schizophrenia. Arch Gen Psychiatry 63: 267-272.

26. (2013) American Psychiatric Association (APA). Diagnostic and Statistical Manual of Mental Disorders. (5 ${ }^{\text {th }}$ edn.) American Psychiatric Association, Washington DC, USA.

27. World Health Organization (2011) International Statistical Classification of Diseases and Related Health Problems, $10^{\text {th }}$ Revision. World Health Organization, Geneva, switzerland.

28. Tootoonchi P (2004) Chronic diseases and senile changes in the elderly population. Payesh 3 (3): 219-225.

29. Wallace M (2008) Essentials of Gerontological Nursing. Springer Publishing Company, LLC. New York, USA pp. 145-174.

30.Zubenko GS, Mulsant BH, Sweet RA, Pasternak RE, Tu XM (1997) Mortality of elderly patients with psychiatric disorders. Am J Psychiatry 154(10): 1360-1368.

31. Zgueb Y, Jomli R, Ouertani A, Hechmi S, Ouanes S, et al. (2014) Deaths in a Tunisian psychiatric hospital: An eleven-year retrospective study. Encephale 40(5): 416-422.

32. Räsänen S, Hakko H, Viilo K, Meyer-Rochow VB, Moring J (2003) Excess mortality among long-stay psychiatric patients in Northern Finland. Soc Psychiatry Psychiatr Epidemiol 38(6): 297-304.

33. Gausset MF, Casadebaig F, Guillaud-Bataille JM, Quemada N, Terra JL (1992) Mortality of mentally ill patients. Review of the literature. Encephale 18(1): 93-100.

34. Lim LC, Sim LP, Chiam PC (1991) Mortality among psychiatric inpatients in Singapore. Singapore Medical Journal 32(3): 130-132.

35. Hewer W, Rössler W (1997) Mortality of patients with functional psychiatric illnesses during inpatient treatment. Fortschr Neurol Psychiatr 65(4): 171-181.

36. Tabbane K, Joober R, Spadone C, Poirier MF, Olié JP (1993) Mortality and cause of death in schizophrenia. Review of the literature. Encephale 19(1): 23-28.

37. Abiodun OA (1998) Mortality in a psychiatric population: A Nigerian psychiatric hospital experience. Acta Psychiatr Scand 77(6): 654-657.

38. Kamara SG, Peterson PD, Dennis JL (1998) Prevalence of physical illness among psychiatric inpatients who die of natural causes. Psychiatry Services 49(6): 788-793.

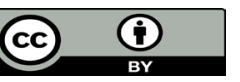

This work is licensed under Creative Commons Attribution 4.0 License

To Submit Your Article Click Here:

Submit Article

DOI: $10.32474 /$ SJPBS.2020.03.000174

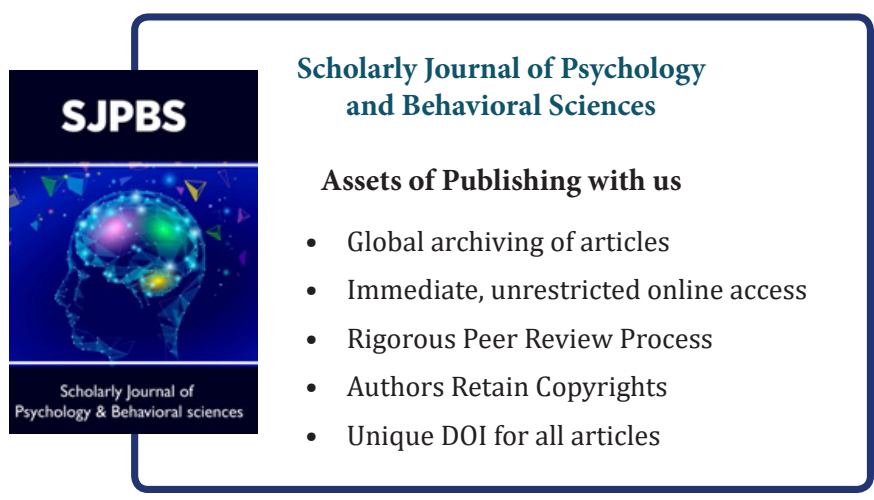

